Terry Janzen*

\title{
Shared spaces, shared mind: Connecting past and present viewpoints in American Sign Language narratives
}

https://doi.org/10.1515/cog-2018-0045

Received 03 April 2018; revised 08 January 2019; accepted 22 January 2019

Abstract: In American Sign Language (ASL) narratives, signers map conceptualized spaces onto actual spaces around them that can reflect physical, conceptual, and metaphorical relations among entities. Because verb tenses are not attested in ASL, a question arises: How does a signer distinguish utterances about past events from utterances within a present conversational context? In narratives, the story-teller's past-event utterances move the story along; accompanying these will often be subjective comments on the story, evaluative statements, and the like, that are geared, in the present, to the conversational partner. This usage-based study looks at how the ASL signer integrates past and present spaces in a narrative and specifically, integrates the viewpoints associated with each. Blending past and present spaces, while a conceptual notion, is in ASL played out in utterance structure and also in the fact that signed language articulation takes place in a three-dimensional space upon which both the signer and addressee have embodied, perspectivized views. Past and present conceptual spaces both occupy the physical space of articulation, and so the blends are at once conceptual and perceivable.

Keywords: ASL, blended spaces, simultaneity, viewpoint, body partitioning

\section{Introduction}

In American Sign Language (ASL) narratives, signers build scenes in part by conceptualizing the scene space and mapping their discourse entities and actions to a relational version of that space in their articulation space. The articulation space is a physical space that includes the signer, and thus the signer's body, such that the signer takes on the various viewpoints of the characters in the narrative scene (Janzen 2004, Janzen 2006, Janzen 2012). These perspectivized enactments, then, are the constructions in the narrative

*Corresponding author: Terry Janzen, Department of Linguistics, University of Manitoba, Winnipeg, Canada, E-mail: terry.janzen@umanitoba.ca 
sequence that push the past action forward, and the spatial referencing represents a dynamic past space. But within narrative, the narrator also inserts descriptive passages, evaluates aspects of the unfolding past event, and frequently checks in with her interlocutor to make sure they understand each other. These aspects of narrative structure take place in the present between storyteller and addressee, and are regularly interspersed throughout the narrative. These elements are intersubjective in that they represent interactions between interlocutors that shape their joint view of the narrative story (Janzen 2012).

In this study, I look at how the ASL signer integrates past and present spaces, and in particular, integrates the viewpoints associated with each, that is, viewpoints of various characters in the past event along with the narrator's present discourse space viewpoint. Differentiating between past and present proves somewhat challenging, because ASL does not mark tense on the verb. There has been one proposal (Jacobowitz and Stokoe 1988), however, that suggests there is verbal tense marking, but this proposal is problematic for a number of reasons. Jacobowitz and Stokoe claim that past is marked by articulating the verb in a space somewhat lower and closer to the body, and future by articulating the verb in a somewhat higher space extended away from the body. But this analysis does not take into account that in narratives based on past events that have taken place in real spaces, relational aspects of those realworld spaces are mapped onto the signer's present articulation space in the retelling and further, it appears that conceptualized proximity or distance from the signer motivates particular spatial placements. These elements in ASL narratives frequently contravene Jacobowitz and Stokoe's proposal, and are examined in more detail below.

Because there has not yet been convincing evidence for an inflectional tense system in ASL, other analyses of time referencing that are typically explicated in ASL grammars (e.g., Baker and Cokely 1980; Valli and Lucas 1992; Valli et al. 2005) suggest that time-frames are set by temporal phrases, most often given at the beginning of an utterance. The time-frame is then understood to remain until another temporal phrase is used. This discourse mechanism does occur, but below it will be shown that it is not obligatory, and is not the default as is typically claimed. An example of how this mechanism is used, however, is given below in Figure 1.

Figure 1 represents the beginning of a narrative passage with the signer setting a time frame for the story. It should be noted that signers tend to do this when a specific time period is intended for the story, but this is not a discourse requirement for this genre, as the examples in sections below show.

In the present study, I examine how signers do establish when something is understood to be a past event, and therefore in a "past space” conceptually, and 


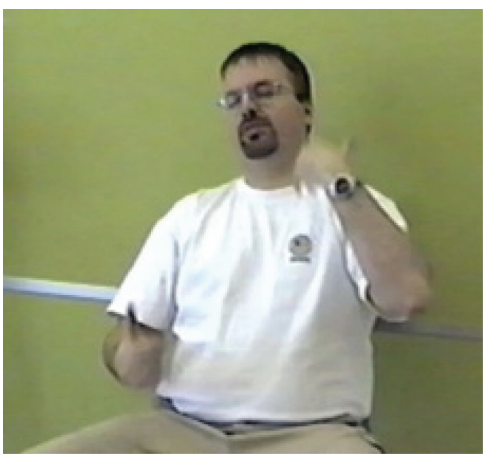

(a)

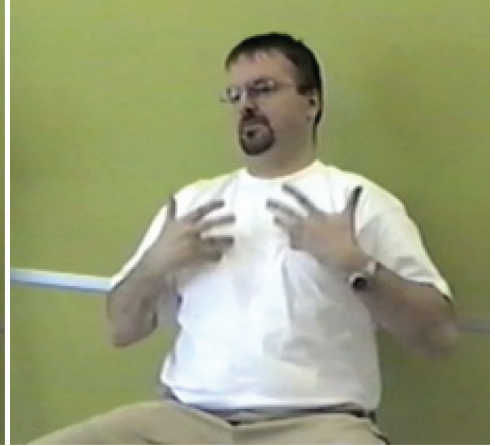

(b)

Figure 1: In (a) the signer signs LONG.AGO (or PAST), and in (b) YOUNG, with the construction meaning 'long ago (when) I was young'.

when something is in the present, thus a "present space". In narratives a pastoccurring story is told, although throughout the story-teller comments on, describes, and evaluates aspects of the story, in effect, perspectivizing the event from a present, subjective and intersubjective point of view. So it can be seen that even though a narrative passage is set in the past, narrators make numerous and rapid shifts between past and present spaces.

Against the backdrop of the claims of temporal adverbial phrases as setting time-frames in ASL discourse (Baker and Cokely 1980; Valli and Lucas 1992; Valli et al. 2005) and the proposal for tense marking in Jacobowitz and Stokoe (1988), the present study examines how ASL signers-as-narrators establish timeframes in their narratives, and yet maintain connections with the present space that includes the narrator and addressee. I look at how a narrative is introduced, whether temporal phrases initiate time-frame changes in usage-based conversational discourse, and the relationship between tenseless verbs and inferencing on the part of both signer and addressee.

In Sections 2 and $3 \mathrm{I}$ introduce several ideas that are foundational for examining past narrative and present narrator spaces, that is, the embodied viewpointed nature of spaces in ASL discourse in Section 2 and the role that body partitioning (Dudis 2004) plays in the representation of blended past and present spaces in Section 3. Section 4 describes the data examined in this study, including the "mouse story" from the conversational corpus of ASL, and from which the complex examples of past and present spaces are taken. In Sections 5 and 6 we see how in the conversational narratives the narrator represents present and past spaces, and integrates them as blended spaces, 
both conceptually and within the physical space a signed language is articulated. Section 7 concludes the discussion.

\section{Viewpointed spaces}

In ASL, as in all signed languages, articulation takes place within the space surrounding the signer, and importantly, that space includes the signer as a deictic centre. In signed languages, we are able to see overtly, perhaps to a greater extent than for spoken languages (except when we include speakers' gestures), the embodiment of language especially in terms of viewpoint expression. Signers have a view of their surrounding physical space, into which they map their conceptualizations of past spaces and the events, movements, and relationships of entities that populate those past spaces. Just as the signer's body, along with a physical and mental viewpoint, is central within a present space, the signer can assume similar viewpoints of her past self in a past space, or in fact of any conceptualized, viewpointed entity in a past space. Janzen (2004, 2012) demonstrates that in narrative discourse, signers mentally rotate past spaces such that they bring story characters' viewpointed spaces into alignment with their present bodily stance, and alternate between those character viewpoints as they interact with one another in the past narrative event. Enacting such perspectives is always a subjective choice, but these choices are also intersubjective in that the signer in effect asks the addressee to see the story as she is seeing it, in other words, invites the addressee to adopt a particular (subjective) perspective on the scene. Tversky (1996) concludes, however, based on experiments concerning deixis and viewers' viewpoints on object relations (e.g., 'in front of', 'to the left of', etc.) that when the speaker takes the addressee's perspective, it "should make communications more likely to be understood" (1996: 470). But it is evident that signers do not adopt the perspective of the addressee in narratives, such that the addressee is asked not only to understand the story through the signer's eyes, but also to view the actual physical articulation space from the signer's embodied viewpoint. This is in keeping with Emmorey's (2002) study on signers' signed descriptions of living spaces, in which Emmorey manipulated the signers' descriptions to be either from their own or the addressee's point of view, finding that addressees clearly preferred the descriptions of space from the signer's view. In other words, their preference was to rotate their own point of view to align with that of the signer. This must come at some cognitive cost (Clark and Brennan 1991) to the 
addressee, but as discussed below, in the case of signers bringing narratives into their conversations, the assumption is that the addressee was not present at the past event being described, so there may not be any logical reason for the storyteller to consider aligning the viewpoint on the scene with that of the addressee in a present space.

However, the addressee's viewpoint must also be considered (see Sanders and van Krieken, 2019), as the addressee is drawn into the story and is invited to adopt the narrator's subjective viewpoint. As mentioned above, addressees in ASL discourse seem to prefer to adapt to the signer's viewpoint in a description of a scene, but the interplay between signer and addressee during a narrative sequence is complex, as will be seen in the examples described below. The signer's viewpoint is privileged, in that it is she who determines which subjective linguistic, prosodic, gestural, and spatial choices are made, but these choices are also intersubjectively motivated-as narrator she wishes the story to have some particular effect on the addressee. As will be seen below, the narrator closely involves the addressee in the narrative event, and as Tversky (1996: 467) notes, "perception and cognition begin with the viewer's perspective".

Verhagen (2019) shows how storytellers using a tensed language, such as English, have available to them the historical present, which brings more of an immediacy and argumentative relevance to the story, placing it closer to the addressee's conceptualized perceptibility than does using the past tense. Lu (2019) discusses Mandarin, an untensed language, where speakers do not have the same choices. Lu claims that narrative storytelling in Mandarin thus more consistently lends the narrative such an immediacy. For signed languages such as ASL, I argue, the lack of tense on ASL verbs also contributes a distinct immediacy to a narrative, but more so, the signer's telling and in particular, enacting or depicting narrative scene events, is visible to the addressee, taking place in the physical space in front of her, heightening the immediacy of the story to an even greater extent.

\section{Body partitioning}

An additional, and critical, feature of ASL discourse is that signers partition their bodies from time to time so that some body parts are associated with one entity while other parts are associated with another. This takes place regularly in discourse, but is especially acute in narrative sequences. Dudis (2004) gives the example of an utterance about an interaction between a library patron and a 


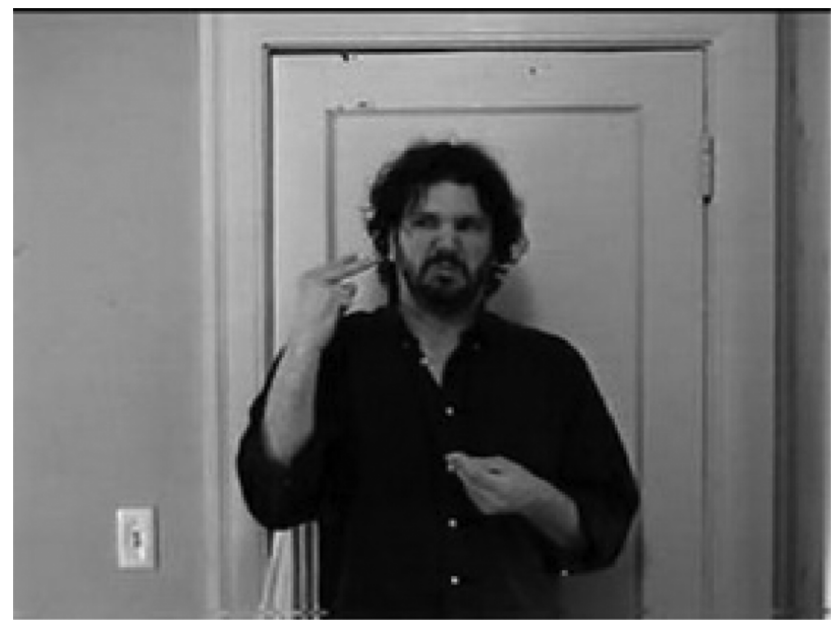

Figure 2: Body partitioning: Librarian and library patron (Dudis 2004: 235).

librarian, where the signer's eyes, body, and left hand (depicted as holding a book) represent the patron, but where both the right hand articulating LOOK.AT, ${ }^{1}$ directed toward the signer's face, and the signer's facial scowl simultaneously represent the librarian, illustrated in Figure 2. Body partitioning in this example thus shows that two actors and their actions-the librarian and the library patron-can be represented by the signer simultaneously, a language feature pervasive in signed language constructions but one that is also available to spoken languages: Dudis alludes to this, and speakers' gestures have recently been analysed as exhibiting body partitioning characteristics as well (Bressem et al. 2018).

Such simultaneous body-partitioned depictions are well documented in signed languages (Vermeerbergen et al. 2007a), but there has not been much analysis of body partitioning across time-frames.

It is evident in these narratives, however, that the signer frequently crosses this time boundary by signing part of a past-space utterance while simultaneously-either by signing something with the other hand, or through facial gestures and eye gaze-commenting on the event in the present discourse space, or "checking in" with the addressee, or asserting that "this is the way

1 ASL signs are notated as upper case English word glosses. Periods between words indicate that more than one word is needed to gloss a single sign. 
it was". This takes place numerous times throughout the mouse story narrative passage described below, and can be seen in other narratives in the corpus.

\section{Data sources}

Data for this study are primarily taken from a corpus of ASL conversational discourse recorded in 2000 at the University of Manitoba, Canada, in a study involving ten deaf L1 signers in the Winnipeg deaf community. The conversationalist dyads knew each other well, their discourse style is casual, and the narratives being told are unrehearsed. Both conversationalists in the dyads were deaf, claimed ASL as their first language, identified as members of the local deaf community and were identified by others as belonging to that community. All began acquiring ASL at an early age and used ASL daily. The narratives are embedded in the conversations, with the signers free to talk about anything they wished. The signers were unaware that one focus of the project was to examine narrative structure.

While the current study draws mainly from one narrative example, the "mouse story", the discussion of which begins in Section 5.1 below, one complementary example from Irish Sign Language (ISL) discourse is included for comparison, because it illustrates a comparable use of deictic space, suggesting that the deictic principle discussed below may occur in signed languages beyond ASL. The mouse story well exemplifies how signers signal past and present spaces throughout the corpus, thus it was chosen for detailed analysis here.

\subsection{The mouse story}

The mouse story takes place during the signer's childhood, when her deaf family was vacationing one summer. They were enjoying an evening together while her father prepared dinner, chopping vegetables at an outdoor grill with a brick chimney. At one point her father sees a mouse climbing down the chimney just above the grill, and he reacts by impulsively swiping at it with his knife, inadvertently chopping the mouse's head off, spattering blood on all the food on the grill. Dinner is ruined.

The story begins with the signer asking her addressee if she would like a story about a mouse, thus introducing the genre of narrative embedded in their conversation. We take up this point in Section 5, and look at how the signer establishes a past space first as something distant in time and location, but 
then repositions the story space to represent it as currently relevant, in a central and proximal space. This discussion begins in Section 5.1.

\section{Setting the time-frame: Past spaces in an ASL narrative}

Given that ASL verbs are not marked for tense, how is the past space set when a narrative begins? Certainly, consistent with the idea that a temporal phrase is used to set a time-frame, ASL signers do this. This was shown in Figure 1 in Section 1 above, from another narrative in the ASL corpus described above.

The single temporal marker used in the introduction of the mouse story comes about ten utterances in, after she has established who is involved and where they were going. She says (translated roughly) 'at that time ... ', which is not itself a specific time- or tense-setting phrase, but a deictic marker indexing her prior assertion that they used to go to this camp regularly, thus inferring a past time period. Thus it appears that the past space is set pragmatically and contextually, and understood largely through inferencing. The signer actually introduces the story by first asking "do you want a story about a mouse? ... not at home, but at the 'deaf camp"”. These orientation clauses (Stubbs 1983) indicate expected discourse structure-that what is to follow is a narrative genre, and narrative stories are typically positioned in the past. In ASL, as discussed below, inferencing is an important mechanism in understanding both the time-frame of the narrative altogether and time-frame changes in story segments. We might expect that anything that deviates from the frame might need to be overtly stated, but as we will see, even this is not necessarily the case.

\subsection{Spatial perspective-setting: Viewing the past from the present}

Significantly, in this ASL narrative, the mouse story, the past space is set through a change in spatial perspective. Initially, when the signer signs EVERY.YEAR GO GO HOLIDAY DEAF.CAMP PRO.3 ONTARIO ${ }^{2}$ 'every year we go (went) on a holiday to the 'deaf camp' in Ontario', she signs the reduplicated

2 The reduplication of GO indicates iterative or habitual aspect. PRO.3 is a third person singular pronominal point. 


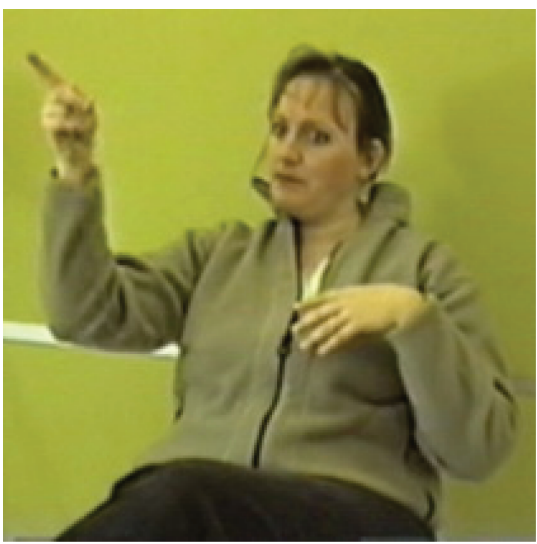

(a)

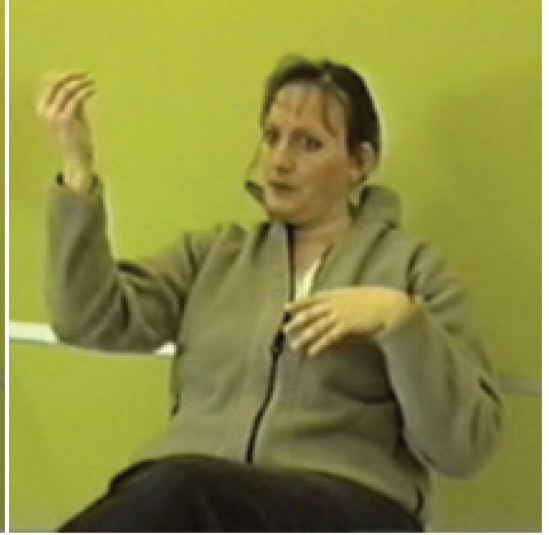

(b)

Figure 3: Indicating the Ontario location as a distance space, in (a) by indexing the location with a raised and extended point, and in (b) by positioning the sign ONTARIO in a similarly high, outward location.

verb GO GO in an outward direction to the right of centre, followed by PRO.3 (a pronominal point indexing a location) ONTARIO in a high, extended, right-ofcentre location shown in Figure 3. As noted above, this deictic indication of distance lets us know that her perspective includes conceptualizing the location as somewhere distant, in other words, it is conceptualized as distant from herself in the present and of her not currently being at that location. That it is a present-space viewpoint is clear because of the signer's initial eye gaze toward her addressee.

The distant spatial reference is reiterated in a construction a few utterances later, shown in Figure 4. In this case the present perspective is made clearer by the signer looking toward the distal space in Figure 4(a). In effect, now she is looking at the past from a present space, while signing THAT TIME directed toward the distal space, and then once again, her eye gaze returns to the addressee in (4b).

\subsection{The CONCEPTUAL DISTANCE IS SPATIAL DISTANCE metaphor}

In the introductory comments to the mouse story narrative illustrated in Figures 3 and 4 above, the signer conceptualizes that past location of the event about to be described in a distal, elevated location in her articulation space. This spatial choice may reflect something about both the actual distant location in realworld space as well as differentiating the past from the present, but it is clearly 


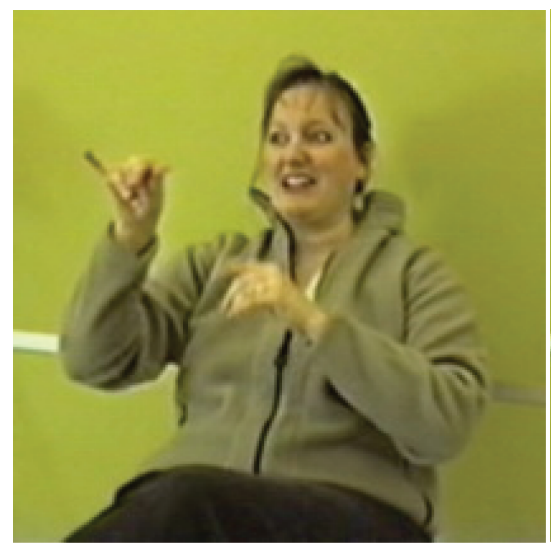

(a)

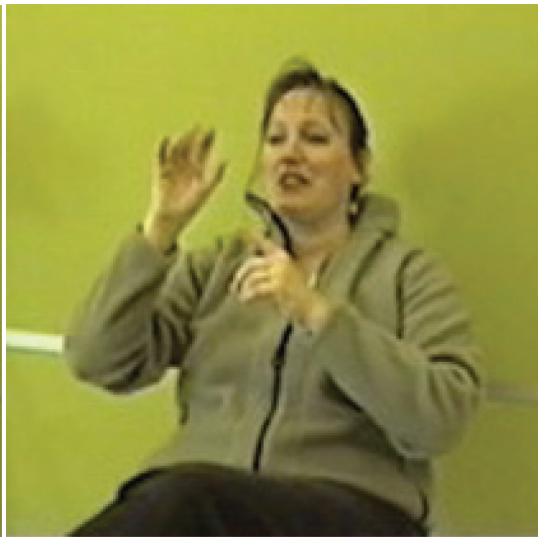

(b)

Figure 4: In (a) the signer's eye gaze is toward the past space; in (b) her eye gaze returns to her addressee.

a metaphorical use, for two reasons. First, regarding past and present, we might note that these are abstract notions that are not inherently spatial, but TIME IS SPACE metaphors are widely attested (e.g., Lakoff and Johnson 1980) in many languages, including ASL (Wilcox 2000). Second, the location where the past event took place is in fact somewhere other than where the narrator is at the time of the storytelling, so the distal spatial location in the present physical space would seem to map onto the conceptualized story-location distance, except for the fact that it is significantly raised, and it is not the case that the location in Ontario is geographically higher than the narrator's current location. Therefore we can postulate that both distal and raised spatial placement play into the metaphor CONCEPTUAL DISTANCE IS SPATIAL DISTANCE.

Shaffer et al. (2017) demonstrate this for both ASL and Irish Sign Language (ISL), where distal spaces are chosen systematically to coincide with conceptually distant ideas and proximal spaces coincide with conceptually closer ideas. In one of their ISL examples, the signer tells a story about taking his car to a mechanic, who is unable to repair it. The car is sent to the mechanic's brother, also a mechanic, and eventually on to yet a third mechanic. The signer begins the story by assuming a perspective of the first mechanic looking at the car's engine in a proximal space directly in front of him, but as the car is sent to the second and third mechanics, the signer indicates increasingly distal spaces, thus representing not just locations that are literally more distant, but less connected to him-he may not even know where these mechanics are. Figure 5 shows the signer pointing to the location of the third mechanic. 


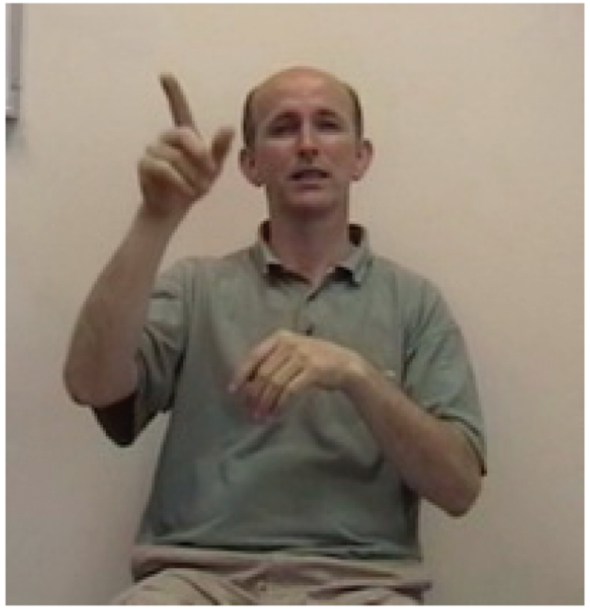

Figure 5: ISL signer pointing to a distal location representing a lesser-known referent.

The spatial location indicated by the point in Figure 5 is more or less identical to the space indicated in the beginning of the mouse story for the location of the camp in Ontario, and once again we see that the extended, raised location of this ISL point is consistent with the metaphor CONCEPTUAL DISTANCE IS SPATIAL DISTANCE. Shaffer et al. (2017) suggest that distant spaces frequently represent entities or ideas that are in some way unknown or unknowable, which the ISL example may well exemplify, in that the signer's car has gone off to some other mechanic, which the signer has had little or no access to. Note that this signer is also talking about a past event, yet his eye gaze is toward the addressee, thus situating the utterance in the present space shared between the narrator and addressee. In the Ontario example, however, the entity is very much known to the narrator, as becomes clear in the narrative, and is quite likely known to the addressee as a member of the same deaf community, which means that the raised location does not align solely with unknown or unknowable entities, as Shaffer et al. have suggested. This means that "conceptually distant" is a more superordinate category, and thus that CONCEPTUAL DISTANCE IS SPATIAL DISTANCE is a more superordinate metaphor that covers numerous, more specific categories. This topic is taken up further in Section 7 below.

\subsection{Inferring the past}

In the mouse story, differing from the example above in Figure 5 and contrary to what ASL grammars have claimed regarding temporal phrases, no time-frame is 


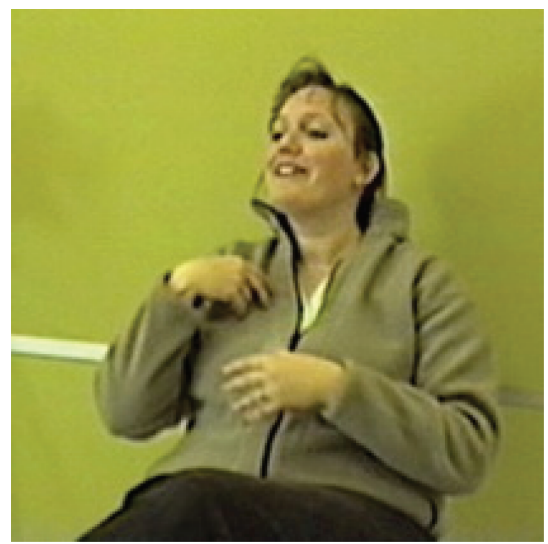

(a)

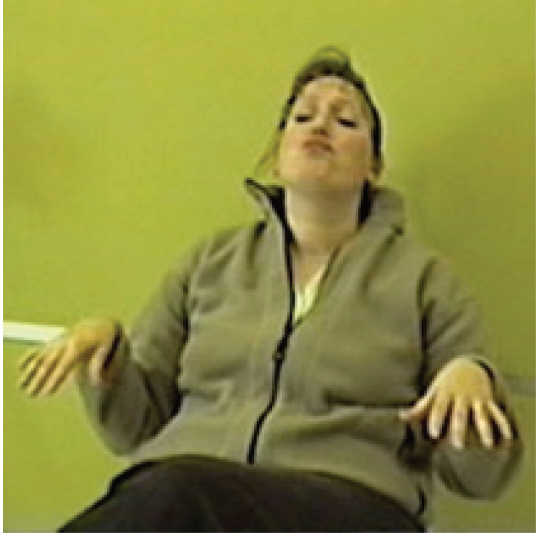

(b)

Figure 6: First person pronominal in (a); depiction of childlike behaviour in (b).

overtly stated at the beginning of any of the opening utterances. The signer states that every year she and her family go (the verb is untensed here) to a deaf community-owned camp in Ontario. She also states that some of them are little kids, including the depiction shown in Figure 6.

Because none of the utterances in the opening segment of this narrative include a specific time reference and because ASL is a language without verbal tense morphology, the verbs here are not tensed to indicate past. The time-frame is therefore not set by any overt markers, and yet we understand that this event has occurred at some time in the past. In Figure 6, the utterance carries the meaning 'I am a young child', which invites the inference of a past time but does not state it overtly. Along with the signer indicating that this is a narrative story, the genre of which is typically about a past event, and the signer's opening statements of

(i) every year we go to the deaf camp in Ontario,

(ii) my relatives all go together,

(iii) (at) that time, and

(iv) I am a young child,

all of which are untensed, the addressee is able to make sufficient inferences to set the event in the past. This is additionally supported by the initial extended and raised location for Ontario, which becomes the spatial reference point toward which the path of the verb GO is directed along with the phrase THAT TIME and the eye gaze accompanying it (Figure 4[a] above). The spatial 
positioning of ONTARIO distinguishes it as a conceptually distant entity from the present space of the time and location of the narration in the conversational discourse.

\subsection{Bringing the past into view}

Following the identification of the location for the mouse story, the signer introduces the first scene in the narrative, that of her father cooking at the grill, which is signed centrally, close to her body, during which she enacts the viewpoint of her father, as in Figure 7(a). Once again there is no overt marker of past time, but the change in spatial orientation indicates a distinct perspective shift from the past location as a distant space to her now being conceptually positioned within the narrative at that location-she has mentally brought the location to align with her present physical stance (Janzen 2012). At the same time, she has conceptually moved from a present time to a past time.

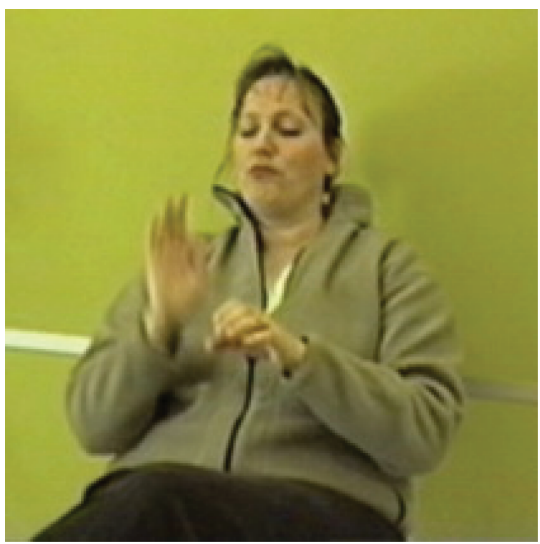

(a)

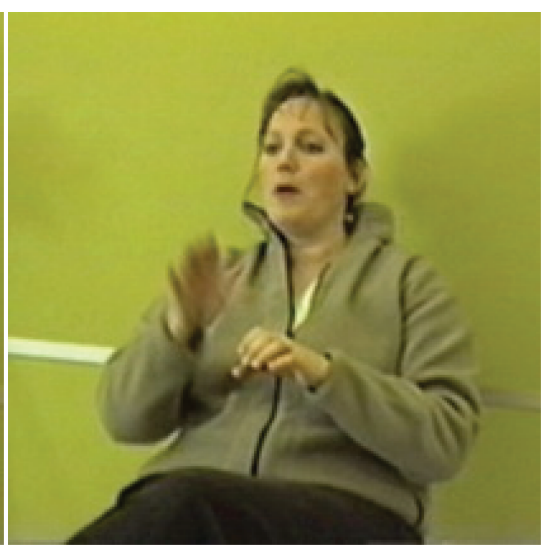

(b)

Figure 7: Enacting the perspective of the father in a conceptual past space in (a); reconnecting to the present space via eye gaze to the addressee in (b).

Figures 3-4 and 7 show a sequence of utterances in which the signer first positions a past space at a distant point from within a present-time perspective, then shifts her eye gaze to this past space from her present space, and finally realigns the perspective to that of being in the past space, chopping mushrooms and looking down at the grill conceptualized as right in front of her. This sequence is shown together in Figure 8. 


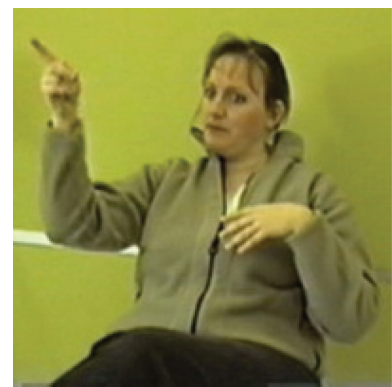

(a)

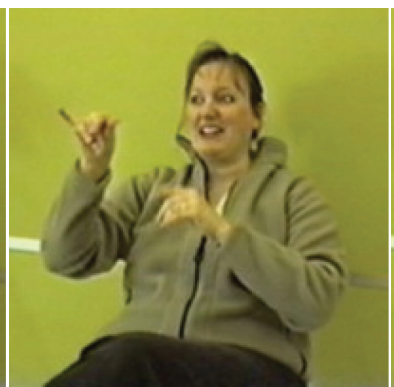

(b)

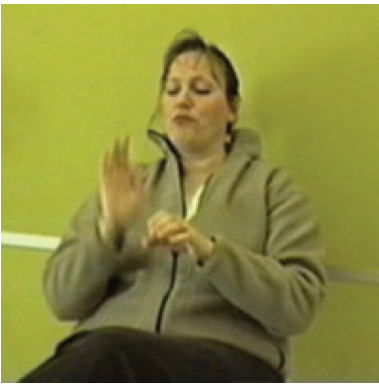

(c)

Figure 8: The distal past in (a), from Figure 3(a); viewing the distal past space in (b), from Figure 4(a); and the proximal past space in (c), from Figure 7(a), showing character viewpoint.

But while maintaining this new perspective and stance, she looks up once again at her addressee, shown in Figure 7(b). Such blended spaces are discussed in more detail in Section 6 below. For the remainder of the narrative, the events continue to unfold in this central space, with the signer depicting character actions, assuming these characters' viewpoints on the scene as she does this. Note that Liddell $(1995,2003)$ refers to depicting sequences as occurring within a “surrogate” space (1995: 27), but I prefer Parrill's (2012, following McNeill 1992) use of the phrase "Character Viewpoint" (2012: 104) in her study of co-speech gesture, and here I examine how narrators blend viewpoints and past and present spaces through body partitioning and eye gaze.

\subsection{Discourse participants' present space}

Figure 7 shows that the signer conceptualizes both the past narrative space and the present discourse space in such a way that she is able to move between these two spaces. We don't learn this from tense marking because this is not a feature of ASL verb morphology, but primarily from eye gaze, that is, when the narrator looks at her addressee she necessarily does so within a present space, and when her gaze coincides with a narrative character's gaze-whether her own past self or that of another character-it is within the past space. As narrator, though, she cannot be in a past space, and likewise a story character in a past space cannot reach into the present storytelling space to gaze at the addressee. This means that even if a narrative time-frame has been set (here inferentially), her discourse moves back and forth between past and present, and the generalization that a time-marker at the beginning of one utterance sets the time frame until it is replaced by another marker (Baker and Cokely 1980; Valli and Lucas 1992; 
Valli et al. 2005) does not appear to hold, and is perhaps not relevant here. The signer appears to be able to do this even within a single clause, which will be discussed below.

The distinction between eye gaze to the addressee for present time and eye gaze around the signer's articulation space for past time does not seem to be absolute, however. In particular, within a present space, the signer can still view past elements positioned in the physical space from the present, as can the addressee. An example shown earlier is in Figure 4(a) in Section 5.1, where the deictically distant space that holds the far-off location of the past event, conceptualized from the signer's present standpoint, has the signer's gaze. One possibility is that the signer is at that point both remembering and planning how to embark on her story; she pauses briefly while gazing toward that location. But it could also have the effect of increasing the salience of the past space for both her as narrator and the addressee. Again, if the narrator can gaze at the spatial location as representing a past space, the addressee could also conceptualize this distally-located entity. In Figure 3, showing how the signer introduces the camp in Ontario and locating her sign ONTARIO and indexing it at a raised and outward location, it is somewhat significant that she does not glance at that space at first: the location is far away for both discourse participants in the sense of Shaffer et al.'s (2017) conceptually distant space. But in the utterance in Figure 4, that location is brought conceptually closer. She can "see" it and, in effect, so can the addressee. We know from studies on intersubjectivity (e.g., Brinck 2008) that joint attention to a third entity is achieved when a speaker intentionally draws the addressee's attention to it successfully, and this can be through a gestural action such as pointing. "The act of nonverbal reference, with the function of directing the observer's attention to a distal target, is the paradigmatic example of intentional communication" (Brinck 2008: 120). However, the distal location of the past space at the beginning of the narrative is still salient because it falls within the CONCEPTUAL DISTANCE IS SPATIAL DISTANCE metaphor, so we might say that directing joint attention is intersubjectively intentional, but so is the significance of the subjectively chosen metaphor.

As Figure 7 shows, the past space of the narrative event is no longer distant at all, but has come to be a front-and-centre space, accessible visibly to both narrator and addressee, within which the narrator is now enacting parts of the past scene. Within the spatial/conceptual domain of the metaphor, this new proximal space represents something conceptually much closer to the signer. There are other instances too where the distinction between gazing at the addressee in a present space and gazing elsewhere around the articulation space in a past space overlaps within a given construction, several examples of which are discussed below as blended spaces. 


\subsection{Moving from a past space to an earlier past space: Emphasizing the role of inference}

Another narrative in the ASL conversational corpus allows us to see how the same principles discussed so far take us from one past space to another, again without the use of specific temporal phrase referencing. The role of inferencing in order to understand the sequence is of equal importance in this case. In this conversation, the signer has developed a comparative-spaces discourse, described in detail in Janzen (2012). The comparison is between his brother and his boss, both of whom work in the millwork industry. At one juncture, the signer breaks from the comparative frame to tell a story about his boss. Janzen (2012) describes a significant change in how space is used at this point. In the comparative frame, the brother is positioned in a leftward space and the boss in a rightward space. Both are being considered in an abstract sense, that is, what each of them is characteristically like, thus not represented as occupying any real space. Once the narrative begins, however, which is about an actual interaction between the signer's boss and himself, and where the interactants were positioned in a real-world relational space, the interaction is represented within a "rotated space" (Janzen 2012), where the boss and the past-self of the signer are both enacted from a character viewpoint in a face-to-face interaction, with both character viewpoints aligning with the narrator's viewpoint. This realignment takes place following the utterance shown in Figure 9.

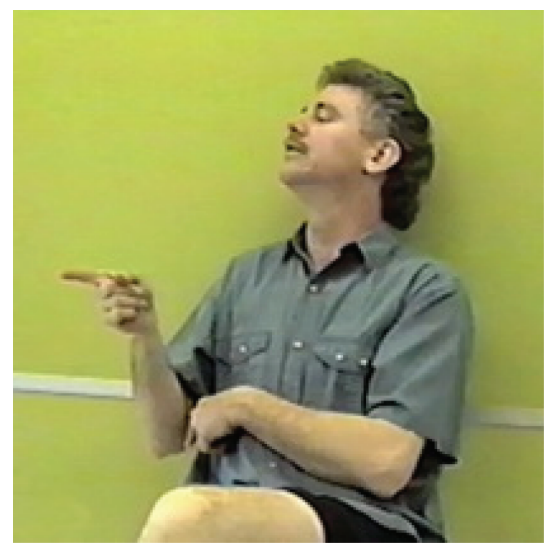

(a)

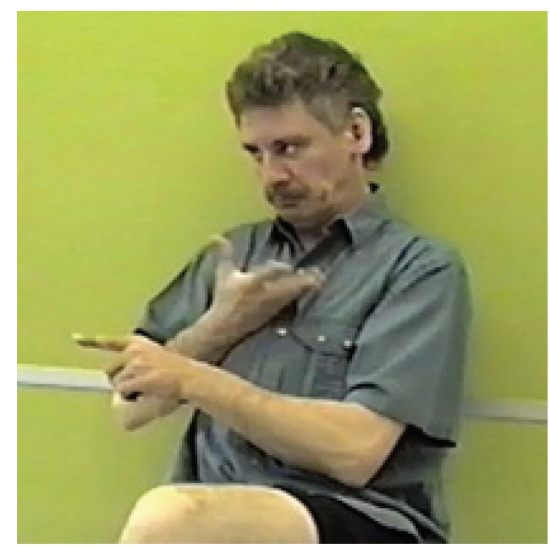

(b)

Figure 9: A point toward the spatial location of the boss in (a), and a combined point (left hand) and the articulation of the verb INFORM directed from the direction of the boss toward the signer in (b). 
Figure 9, which shows the utterance PRO.3 INFORM 1 'he told me', ${ }^{3}$ represents the first utterance introducing the narrative passage. The comparative sequence just previous to this is not time marked, meaning that the characteristic description of the brother and the boss is not time dependent, so could well be interpreted as being in the present. The utterance PRO. 3 INFORM $_{1}$ represents a move to the past, however, but again the verb is untensed and there is no overt mention of time, necessitating an inference on the part of the addressee that we have now moved into a past space. The signer's eye gaze especially in (9b) indicates a character viewpoint not evident in the comparative frame just prior to this, which also may signify a move from a present to a past space.

The signer then abruptly signs PRO.1 TALK ..., illustrated in Figure 10.

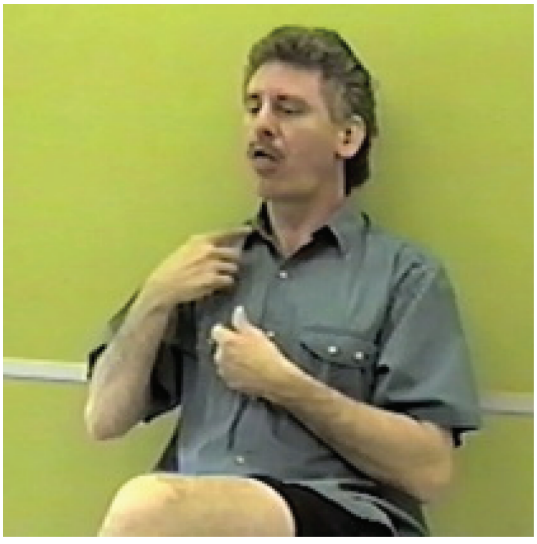

(a)

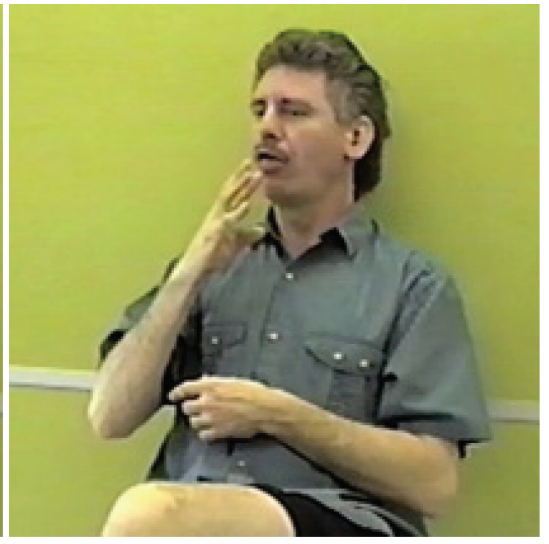

(b)

Figure 10: First person reference PRO.1 in (a), the verb TALK in (b).

The utterance shown in Figure 10 has the sense 'I had been talking about ... ', which represents an earlier event relevant to the story. The time-frame transition, though, is not signalled by an overt marker, leaving the addressee to rely once again on inferencing to understand this. The only significant difference between the utterances in Figures 9 and 10 is the shift in eye gaze. The eye gaze shown in Figure 9(b) is a move from eye gaze to the addressee during the comparative frame sequence just preceding it to a character perspective, and while the utterance in Figure 10 has to do with an event in the past-space narrative, the return eye gaze to the addressee in Figure 10(b) sets this

3 Subscript ' 1 ' on INFORM $_{1}$ indicates that the path movement of the verb is toward the signer. 
utterance off as a present discourse comment on an aspect of the story. Thus, we see that the time-frame distinction between the two utterances is not signalled by overt temporal phrases or a difference in distal-proximal spatial positioning as an indicator of tense, but apparently through a difference in eye gaze that links the past-in-the-past construction to a present-space utterance, and relies on inferencing on the part of the addressee to understand the temporal sequencing.

\section{The presence of the past: Integrating present and past spaces}

As shown above, the narrator of the mouse story moves between past and present spaces, but as she does so, she almost always maintains at least some overt connection to the past. This is accomplished through blending past and present spaces, body partitioning, and simultaneity. Body partitioning was described above in Section 3 as instances of the signer using some parts of her body to represent one entity and other parts to represent a different entity (Dudis 2004) simultaneously. Simultaneity has been identified as a feature of signed languages that appears to differentiate them from spoken languages, perhaps typologically in the sense that the visual mode of language perception allows for multiple body parts (two hands, face and head, torso) to participate in the articulation system, thus potentially more than one semantic unit can be articulatorily represented simultaneously (Brentari 2002), although Vermeerbergen et al. (2007b) caution that when gesture is considered along with speech, some degree of simultaneity may be present in speakers' discourse as well. Nonetheless, here we see evidence of body partitioning and aspects of simultaneity that cross time boundaries, which has not been considered in these areas of study to date, although the analysis of ASL evidentiality strategies in Shaffer (2012) clearly shows similar past/present blends. Here I describe several such blends in the mouse story.

\subsection{Checking in with the addressee}

In Figure 7 above, I noted that the narrator is at that point enacting a past event from the perspective of her father who at the time was chopping mushrooms. The construction used to portray this event is a single perspectivized verb: 


\section{(1) AGT.POV.CHOP++.PAT ${ }^{4}$ \\ '(he) chopped (them)'}

This construction exemplifies Slobin's (2006) claim that in ASL nominals are not obligatory with such verbs if the referents can be recovered from prior discourse or pragmatically, and thus the verb stands alone as a complete clause. However, the signer follows this by fingerspelling M-U-S-H-R-O-O-M, so that the patient (or object, syntactically) may in fact be included in the clause as in (2):

(2) AGT.POV.CHOP++ M-U-S-H-R-O-O-M

'(he) chopped mushrooms'

However, as Figure 11(a) indicates, at the juncture where the narrator begins to fingerspell 'mushroom' her gaze returns to her addressee and at the end of fingerspelling this word, she pauses with a slight questioning expression.

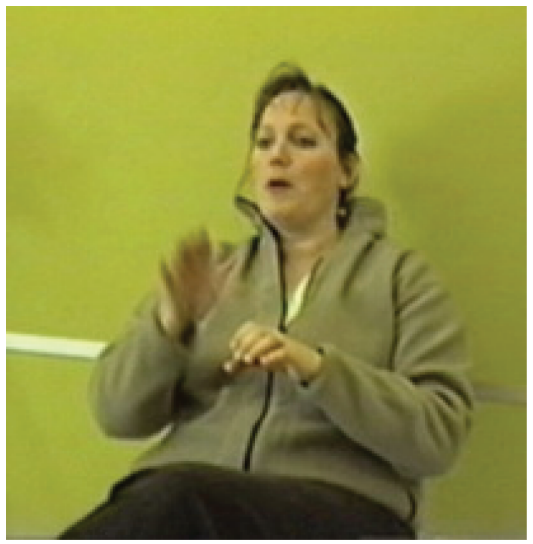

(a)

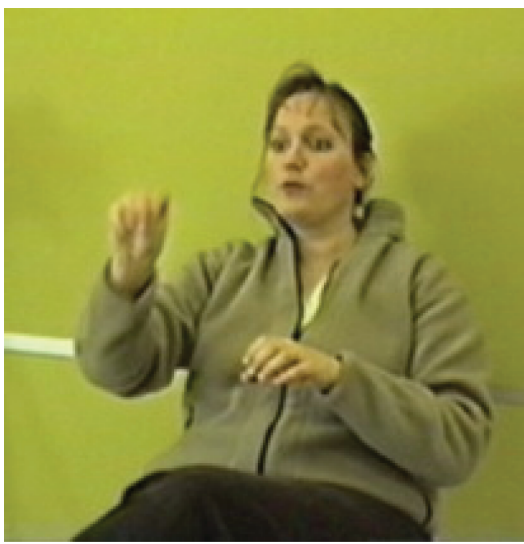

(b)

Figure 11: The narrator in (a) returning eye gaze to the addressee; the pause and slight questioning expression at the end of fingerspelling 'mushroom' in (b).

4 AGT.POV indicates an agent-of-action point of view. Plus signs (++) indicate repeated movement of the sign. PAT following the verb means that a patient is being acted upon, which in this clause is not specified overtly but is represented by the signer's left hand. Letters with dashes, as in (2), indicate fingerspelling. 
This, I suggest, indicates that the past-space utterance is a complete clause as (1) above, and M-U-S-H-R-O-O-M 'mushrooms' is a second utterance supplying information to the addressee-she is checking in by returning to a present space, signalled by her eye gaze. Of importance, however, is that in Figure 11(b), in a present space/past space blend, the left hand remains from the enacted scene of chopping, and so the past space is still visible and active to both narrator and addressee, and the two spaces are thus blended by simultaneity in articulating this construction, and by body partitioning, where the left hand represents the father's hand in the past-space chopping event, and the eye gaze and right hand fingerspelling the word is consistent with the narrator within the present space.

\subsection{Gross!! looking back with disgust}

Figure 12 shows a sequence of utterances about the father and the mouse. In (12a), the father is depicted chopping mushrooms at the grill. A three-way body partitioning is indicated by the signer's head, eye gaze and torso representing the father, the right hand representing the blade of the knife, and the left hand, the surface on which he is chopping. This scene is entirely within a past space, consistent with the narrator-as-father's eye gaze toward the enacted activity. In (12b), the signer describes the mouse descending the brick chimney, with the right hand tracing the path of the mouse down the bricks, and the partitioned left hand (with the hand shape somewhat lax) remaining as an indication of the surface seen in (12a), which may serve as a kind of spatial anchor in the scene. However, the signer's face, and especially her eye gaze, does not now represent

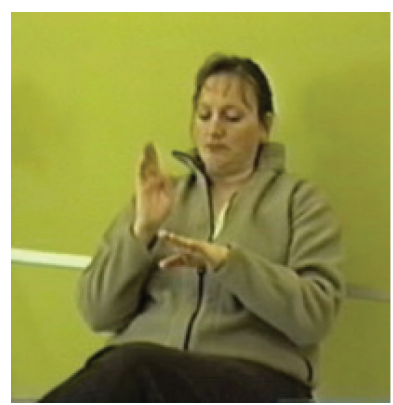

(a)

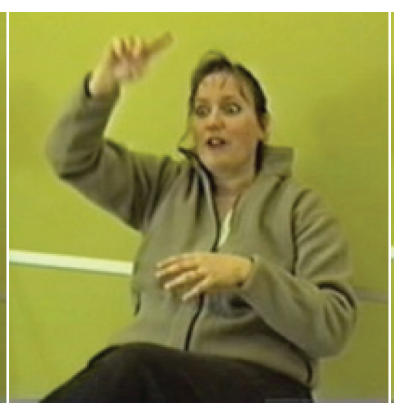

(b)

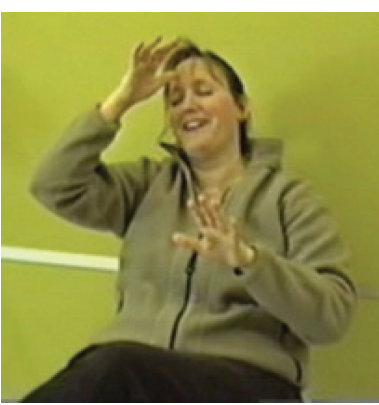

(c)

Figure 12: A sequence of utterances showing the body-partitioned and simultaneous integration of past and present spaces. 
the father at all, but is her present self making eye contact with her addressee, her widened eyes indicating the shock of this taking place from a present point of view. We know this because at this point in the story, the father has not yet noticed the mouse and further, and could not be looking into the present at the addressee. In (12b) we can see the signer blending past and present spaces, and integrating the two perspectives, that of the story character with that of the present-space narrator. This continues and is accentuated in (12c), where she breaks from the storyline altogether to comment 'my father!'-her right hand in (12c) articulates the sign FATHER-along with facial gesture of incredulence and disgust. $^{5}$ This then is a present space evaluation of her father's action. However, with another slight handshape modulation, the left hand remains in the past, keeping the grill-surface anchor: the addressee thus is not completely taken out of the past space-she can still see its body-partitioned anchor represented simultaneously with the present space utterance.

\subsection{Integrating past and present spaces in a single topic-comment construction}

Figures 11 and 12 are but two examples of past and present blended spaces in this narrative. Another case involves a specific construction type, that of topic-comment. Topic-comment constructions are commonplace in ASL discourse (Janzen 1999, Janzen 2018) but they appear to be fairly rare in narrative passages. Occasionally, however, they do occur, and Figure 13 illustrates one such case.

Topic-marked phrases are marked as such for addressees because they represent information that the speaker or signer believes the addressee will be able to identify, and so act as common-ground reference points from which to view the assertion that follows in the comment (Janzen 1999, Janzen 2017, Janzen 2018), and thus are an intersubjective strategy. In this narrative, topicmarked phrases that relate one event to the next, such as the father seeing the mouse climbing down the bricks, truly belong in the past space, moving the storyline along. But topic-marked phrases are invariably accompanied by eye gaze to the addressee, because the topicality of the phrase is a present-space discourse characteristic representing shared information between the signer and

5 An important consideration pointed out by an anonymous reviewer is that this could well be the reaction of those present at the past-space dinner that the signer is reflecting, and while their reaction would most certainly have been one of revulsion, this appears to be a presentspace comment on the father's action because the utterance is expressed before the actual events of the father reacting to the mouse unfold. 


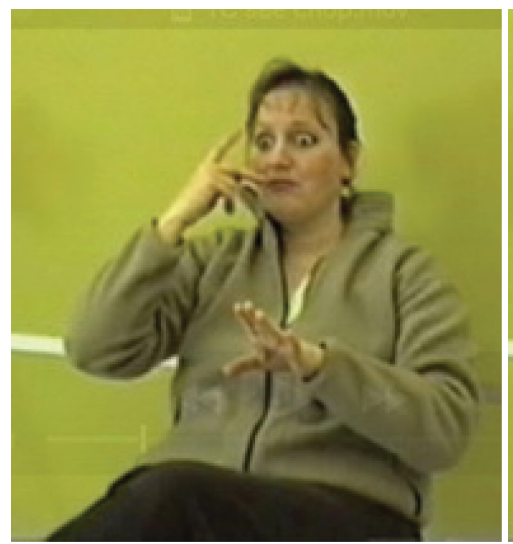

(a)

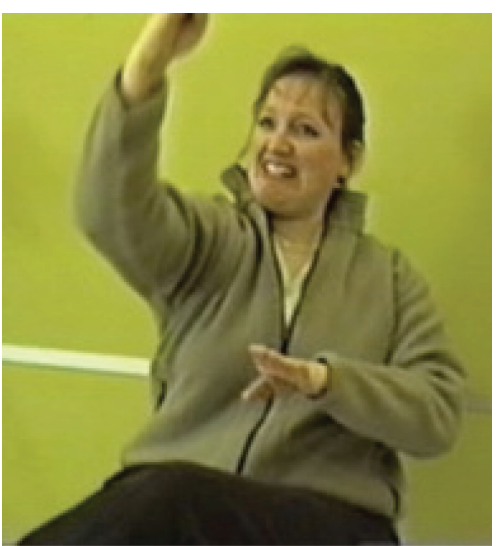

(b)

Figure 13: The topic-marked phrase SEE MOUSE in (a); the comment phrase: A depiction of the father chopping at the mouse, in (b).

addressee. In this case the mouse is already a discourse-grounded referent. The utterance is given in (3).

\section{(3) [SEE MOUSE]-TOP depict:chop ${ }^{6}$}

'As for him seeing the mouse, he chopped at it (with his knife).'

In Figure 13(a) the narrator's body is partitioned in that her left hand represents the grill surface as she simultaneously signs with her right hand the phrase SEE MOUSE, with the intended meaning that her father saw the mouse, which signals the event in the past-space narrative.

But as this is not the first mention of the mouse in the story, the referent would already be identifiable to the addressee. Here the narrator's focus is returning to the mouse following several utterances regarding another subtopic, and so she is bringing the addressee back to this point in the story by topic-marking the phrase, which is a common characteristic of sequenced topicmarked constructions in ASL discourse, functioning intersubjectively as a grammatical device for joint attention (see Verhagen 2008, Verhagen 2019). This is consistent with Verhagen (2005), who comments that grammatical devices can function to manage and assess discourse partners. The signer's eye gaze is squarely on the addressee in the present space shown in (13a), thus we see a

6 The notation TOP means that the phrase inside square brackets is topic-marked with raised eyebrows and eye gaze toward the addressee. depict:chop is a depiction of a chopping motion. 
three-part body partitioning: the grill, the event of the father seeing the mouse (explicated by the sign SEE but not by eye gaze)-both within the past spaceand the narrator in the present interacting intersubjectively with her addressee (eye gaze). In the comment in (13b), the signer returns to the past space, enacting her father chopping at the mouse. Her eye gaze reflects that of her father, while the anchor of the partitioned left hand representing the grill remains as an anchor through the entire topic-comment construction.

\section{Conclusion}

The narratives embedded in ASL conversational discourse illustrate the complex conceptualization of present and past spaces and the frequent blending of these two spaces through the features of simultaneity and body partitioning and importantly, through differential eye gaze that takes the addressee both into the past and into the present. Blending past and present spaces in the ways described above, while a conceptual notion (Fauconnier and Turner 2002) is in ASL played out in utterance structure and the fact that signed language articulation takes place in a three-dimensional space upon which both the signer and addressee have embodied, perspectivized views. Past and present conceptual spaces are mapped onto the physical space of articulation, and so the blends are at once conceptual and perceivable in a signed language.

Because ASL is a tenseless language, that is, tense is not marked morphologically on the verb, signers do not have the option of situating narrative sequences in the past in the same way as those who use a language that does distinguish between past and present. Verhagen (2019) discusses the availability of the historical present in languages such as English and Dutch, which serves to give a sense of immediacy to the events of the story. Lu (2019) contrasts this with Mandarin, a language that is untensed in much the same way as ASL. Lu suggests that this results in more consistent immediate "vividness" precisely because of the lack of time-related (i.e., past) constructions. However, one proposal for a tense system in ASL (Jacobowitz and Stokoe 1988) has suggested that verbs articulated in an extended and raised space are marked for future, and verbs positioned close to the signer and in a lower space are marked for past. The current study has shown inconsistencies in Jacobowitz and Stokoe's analysis and here I propose that a more superordinate deictic principle is embodied in the metaphor CONCEPTUAL DISTANCE IS SPATIAL DISTANCE. Thus we see the extended, raised spatial location corresponding to a conceptualized distant and past location/ event, along with the central, proximal location corresponding to the same 
event, but conceptualized as more immediate, more experientially relevant and accessible, with the narrator adopting story character viewpoints blended with the narrator viewpoint in the present narration space. As Shaffer et al. (2017) have shown, distal spaces are regularly associated with entities or ideas that are not present, not overtly identified, unknown, or unknowable. The future fits well within the category of irrealis and therefore may be referenced articulatorily in a raised, extended space, but this must be understood as just one potentiality of many that fall under the CONCEPTUAL DISTANCE IS SPATIAL DISTANCE metaphor.

This study also shows that body partitioning (Dudis 2004) occurs at the blended junctures of past and present. As the signer produces utterances in the present, directed toward the addressee, parts of her body-perhaps a hand, a bodily stance, etc.-maintain a past time perspective. In this way, multiple perspectives are presented simultaneously that intersect past and present both conceptually and within the physical space in which a signed language is articulated. The usage-based data in this study reveal that signers engage a number of strategies to integrate past and present viewpoints, including not only simultaneously enacted stances and perspectives, but also differentiated utterance types. Character viewpoints correspond to depiction sequences where the signer enacts past actions and talk, while a present-space viewpoint corresponds to utterance types such as topic-comment constructions. In these constructions, the topic phrase contains information the signer assumes the addressee can readily identify, making it an intersubjective marker of present space and present function.

Finally, returning to the sense of immediacy and current relevance that narrators bring to the discourse, Verhagen (2019) argues that the use of past tense (in tensed languages) makes the narrative less relevant to the present for the addressee, whereas the historical present minimizes the distance between the addressee and the story characters. Sanders and van Krieken (2019) likewise claim that when the addressee's viewpoint is aligned with that of narrative passages, engagement with the narrative and its characters is enhanced. And $\mathrm{Lu}$ (2019) speaks about increased vividness that results from time-independent constructions. To this I would add that because a signed language is articulated in the three-dimensional space in front of the addressee, the visual enactment further engages the addressee-she infers the past, but the story is brought from the past to visibly play out in front of her. The narrator, as we have seen, continuously engages with the addressee by blending past and present spaces, including using specific construction types such as topic-comment, and the addressee's view on the space and on the narrative story becomes part of the intersubjective discourse interaction, evoking Gibbs' (2017) notion of the distributed nature of embodiment: "the interactive nature of ordinary language use 
suggests that embodiment is not located within individual brains and bodies, but is shared and coordinated across conversational participants" (2017: 461462).

Acknowledgements: Earlier versions of this paper were presented at ICLC14, ISGS8, and HDLS13 where I benefitted from comments by those attending. Thanks especially to Eve Sweetser, Miako Villanueva, Barbara Shaffer, and Kyra Zimmer. Thanks too, to José Sanders, Kobie van Krieken, and the anonymous reviewers, whose comments helped to greatly improve this paper.

\section{References}

Baker, Charlotte \& Dennis Cokely. 1980. American Sign Language: A teacher's resource text on grammar and culture. Silver Spring, MD: T.J. Publishers.

Brentari, Diane. 2002. Modality differences in sign language phonology and morphophonemics. In Richard P. Meier, Kearsy Cormier \& David Quinto-Pozos (eds.), Modality and structure in signed and spoken languages, 35-64. Cambridge: Cambridge University Press.

Bressem, Jana, Silva H. Ladewig \& Müller. Cornelia. 2018. Ways of expressing action in multimodal narrations - The semiotic complexity of character viewpoint depiction. In Anika Hübl \& Markus Steinbach (eds.), Linguistic foundations of narration in spoken and sign languages, 223-250. Amsterdam: John Benjamins.

Brinck, Ingar. 2008. The role of intersubjectivity in the development of intentional communication. In Jordan Zlatev, Timothy P. Racine, Chris Sinha \& Esa Itkonen (eds.), The shared mind: Perspectives on intersubjectivity, 115-140. Amsterdam/Philadelphia: John Benjamins.

Clark, Herbert H. \& Susan E. Brennan. 1991. Grounding in communication. In Lauren B. Resnick, John M. Levine \& Stephanie D. Teasley (eds.), Perspectives on socially shared cognition, 127-149. Washington, DC: American Psychological Association.

Dudis, Paul G. 2004. Body partitioning and real-space blends. Cognitive Linguistics 15(2). 223-238.

Emmorey, Karen. 2002. The effects of modality on spatial language: How signers and speakers talk about space. In Richard R. Meier, Kearsy Cormier \& David Quinto-Pozos (eds.), Modality and structure in signed and spoken languages, 405-421. Cambridge: Cambridge University Press.

Fauconnier, Gilles \& Mark Turner. 2002. The way we think: Conceptual blending and the mind's hidden complexities. New York: Basic Books.

Gibbs, Raymond W., Jr 2017. Embodiment. In Barbara Dancygier (ed.), Cambridge handbook of Cognitive Linguistics, 449-462. Cambridge: Cambridge University Press.

Janzen, Terry. 1999. The grammaticization of topics in American Sign Language. Studies in Language 23(2). 271-306.

Janzen, Terry. 2004. Space rotation, perspective shift, and verb morphology in ASL. Cognitive Linguistics 15(2). 149-174.

Janzen, Terry. 2006. Visual communication: Signed language and cognition. In Gitte Kristiansen, Michel Achard, René Dirven \& Francisco J. Ruiz de Mendoza Ibáñez (eds.), 
Cognitive linguistics: Current applications and future perspectives, 359-377. Berlin/New York: Mouton de Gruyter.

Janzen, Terry. 2012. Two ways of conceptualizing space: Motivating the use of static and rotated vantage point space in ASL discourse. In Barbara Dancygier \& Eve Sweetser (eds.), Viewpoint in language: A multimodal perspective, 156-174. Cambridge: Cambridge University Press.

Janzen, Terry. 2017. Composite utterances in a signed language: Topic Constructions and Perspective-taking in ASL. Cognitive Linguistics 28(3). 511-538.

Janzen, Terry. 2018. KNOW and UNDERSTAND in ASL: A Usage-based study of grammaticalized topic constructions. In K. Aaron Smith \& Dawn Nordquist (eds.), Functionalist and usagebased approaches to the study of language: In Honor of Joan L. Bybee, 59-87. Amsterdam/ Philadelphia: John Benjamins.

Lakoff, George \& Mark Johnson. 1980. Metaphors we live by. Chicago and London: University of Chicago Press.

Liddell, Scott K. 1995. Real, surrogate, and token space: Grammatical consequences in ASL. In Karen Emmorey \& Judy S. Reilly (eds.), Language, gesture, and space, 19-41. Hillsdale, NJ: Lawrence Erlbaum.

Liddell, Scott K. 2003. Grammar, gesture, and meaning in American Sign Language. Cambridge: Cambridge University Press.

Lu, Wei-Lun. 2019. Time, tense and viewpoint shift across languages: A Multiple-Parallel-Text approach to "tense shifting" in a tenseless language. Cognitive Linguistics 30(2). https://doi.org/10.1515/cog-2018-0039

Jacobowitz, E.Lynn \& William C. Stokoe. 1988. Signs of tense in ASL verbs. Sign Language Studies 60. 331-340.

McNeill, David. 1992. Hand and mind: What gestures reveal about thought. Chicago and London: Chicago University Press.

Parrill, Fey. 2012. Interactions between discourse status and viewpoint in co-speech gesture. In Barbara Dancygier \& Eve Sweetser (eds.), Viewpoint in language: A multimodal perspective, 97-112. Cambridge: Cambridge University Press.

Sanders, José \& Kobie van Krieken. 2019. Traveling through narrative time: How tense and temporal deixis guide the representation of time and viewpoint in news narratives. Cognitive Linguistics 30(2). https://doi.org/10.1515/cog-2018-0041.

Shaffer, Barbara. 2012. Reported speech as an evidentiality strategy in American Sign Language. In Barbara Dancygier \& Eve Sweetser (eds.), Viewpoint in language: A multimodal perspective, 139-155. Cambridge: Cambridge University Press.

Shaffer, Barbara, Lorraine Leeson \& Terry Janzen. 2017. What I know is here; what I don't know is somewhere else: Deixis and gesture spaces in American Sign Language and Irish Sign Language. Paper presented at the International Cognitive Linguistics Conference 14, Tartu, Estonia, July $10-14$.

Slobin, Dan I. 2006. Issues of linguistic typology in the study of sign language development of deaf children. In Brenda Schick, Marc Marschark \& Patricia Elizabeth Spencer (eds.), Advances in the sign language development of deaf children, 20-45. Oxford/New York: Oxford University Press.

Stubbs, Michael. 1983. Discourse analysis: The sociolinguistic analysis of natural language. Chicago: The University of Chicago Press.

Tversky, Barbara. 1996. Spatial perspective in descriptions. In Paul Bloom, Mary A. Peterson, Lynn Nadel \& Merrill F. Garrett (eds.), Language and space, 463-491. Cambridge, MA: The MIT Press. 
Valli, Clayton \& Ceil Lucas. 1992. Linguistics of American Sign Language: A resource text for ASL users. Washington, DC: Gallaudet University Press.

Valli, Clayton, Ceil Lucas \& Kristin J. Mulrooney. 2005. Linguistics of American Sign Language: An introduction. Fourth Edition ed. Washington, DC: Gallaudet University Press.

Verhagen, Arie. 2005. Constructions of intersubjectivity: Discourse, syntax, and cognition. Oxford: Oxford University Press.

Verhagen, Arie. 2008. Intersubjectivity and the architecture of the language system. In Jordan Zlatev, Timothy P. Racine, Chris Sinha \& Esa Itkonen (eds.), The shared mind: Perspectives on intersubjectivity, 307-331. Amsterdam/Philadelphia: John Benjamins.

Verhagen, Arie. 2019. Shifting tenses, viewpoints, and the nature of narrative communication. Cognitive Linguistics 30(2). https://doi.org/10.1515/cog-2018-0058.

Vermeerbergen, Myriam, Lorraine Leeson \& Onno Crasborn (eds.). 2007a. Simultaneity in signed languages: Form and function. Amsterdam/Philadelphia: John Benjamins.

Vermeerbergen, Myriam, Lorraine Leeson \& Onno Crasborn. 2007b. Simultaneity in signed languages: A string of sequentially organized issues. In Myriam Vermeerbergen, Lorraine Leeson \& Onno Crasborn (eds.), Simultaneity in signed languages: Form and function, 1-25. Amsterdam/Philadelphia: John Benjamins.

Wilcox, Phyllis P. 2000. Metaphor in American Sign Language. Washington, DC: Gallaudet University Press. 